\title{
PROCEDIMIENTO EJECUTIVO Y VENTA FORZADA Comentarios al Libro Embargo y Realización de Bienes de Luis Gonzalo Navarrete
}

\author{
Hernán Corral Talciani \\ Profesor de Derecho Civil \\ Universidad de los Andes
}

\section{1.- Cumplimiento de las obligaciones y responsabilidad del deudor}

El cumplimiento de las obligaciones civiles es uno de los requisitos fundamentales para el buen funcionamiento de todo el sistema de derecho privado. La protección del interés del acreedor en obtener el pago de su crédito pero sin descuidar el respeto a la autonomía patrimonial y la dignidad personal del deudor, ha sido uno de los problemas constantes con el que el legislador ha debido habérselas a lo largo de la historia. No hay dificultades cuando el cumplimiento se produce oportuna y voluntariamente por el obligado, pero ¿cómo resolver la negativa de aquel deudor que, por tan diversas razones, se resiste a cumplir sus compromisos pecuniarios?

Métodos expeditivos que sancionaban al deudor con la pérdida de su libertad, hoy son considerados inhumanos, y el legislador prefiere resolver la cuestión acudiendo a la intervención del juez que incauta bienes del patrimonio del obligado, para luego proceder a su venta forzada, (su realización), y con el producto de esa enajenación proveer medios para el pago.

De esta forma, el embargo de los bienes del deudor y su consiguiente realización son instituciones de la mayor relevancia en el proceso civil y que irradian su gravitación a todo el derecho de las obligaciones.

Resulta por este motivo muy afortunado el objeto de la investigación jurídica del profesor Luis Gonzalo Navarrete Villegas, que ha visto sus frutos en esta monografía, la segunda que debemos a su pluma. Se trata de Embargo y realización de bienes, publicada por la Editorial Jurídica de Chile, (Santiago, 1994, 142 págs.). Con un estilo conciso, una elaboración conceptual y sistemática acuciosas, un respaldo bibliográfico y jurisprudencial más que satisfactorio, recorre, sin detenerse en dilaciones que lo apartarían de su objetivo central, todos los tópicos de la ejecución de bienes por cumplimiento de obligaciones que se observan en nuestro procedimiento civil.

Después de una breve introducción sobre la responsabilidad patrimonial del deudor. donde sostiene que ésta no es un elemento constitutivo de la obligación, sino una consecuencia sancionatoria de su incumplimiento, el autor da paso a un análisis detenido de la interesante institución del embargo de bienes. Pasa revista a temas como el objeto del embargo, sus fases, sus efectos, su ampliación, el reembargo, etc. Concluye esta parte con una exposición de los problemas verificados por la incautación de bienes que pertenecen a personas distintas del deudor, y la descripción de los remedios articulados por 
la ley para defender los intereses de estos terceros que se ven envueltos en un proceso de ejecución $\sin$ tener responsabilidad por la deuda cuyo cumplimiento se reclama: las llamadas tercerías de dominio y de posesión. A juicio del autor, estas tercerías no son más que un expediente procesal complejo compuesto de dos acciones que se dirigen simultáneamente frente al acreedor ejecutante y al deudor ejecutado para obtener el lanzamiento del embargo.

\section{El embargo: ¿ acto o proceso?}

En cuanto a la naturaleza jurídica del embargo, el profesor Navarrete escribe que se trata de una actividad compleja integrada por etapas o fases, que él identifica en tres: 1) la búsqueda y selección de bienes. por la que se trata de individualizar bienes embargables del deudor que puedan hacer frente a la ejecución del crédito; 2) la traba del embargo, que consiste en la declaración judicial de que un bien queda afecto al embargo y 3) la garantía de la afección, que pretende asegurar que el bien embargado no sea enajenado o destruido (se incluye aquí el depósito judicial de las especies, la inscripción en el registro conservatorio y la orden de retención al deudor ejecutado).

Que la deuda, sin embargo, acerca de la efectividad de esta construcción compleja del embargo, que siendo muy pedagógica e ilustrativa, ayuda poco a discernir el momento constitutivo de la incautación judicial: ¿cuándo está completo el embargo?, ¿desde cuándo puede decirse que los bienes están embargados y por tanto su enjenación ha sido prohibida? Si nos atuviéramos a la teoría del profesor Navarrete debiéramos considerar que, mientras no se culmine las tres etapas, no habría propiamente embargo, pero el mismo autor se encarga de aclararnos que ciertas medidas de garantía (tercera fase) como la inscripción registral, no empecen a la existencia anterior del embargo: "ya que una vez emitida la declaración de voluntad afectando a un inmueble a la ejecución, el embargo como acto procesal existe todos sus efectos, aunque no se haya practicado la referida inscripción, que solamente es exigida por el artículo 453 para que produzca efectos respecto de terceros" (pag. 32).

Como se ve, pareciera que en realidad el embargo está constituido básicamente por la declaración de voluntad del juez de someter determinados bienes del deudor a la ejecución del crédito. Las etapas de selección de los bienes y la de garantizar su no enajenación no son en realidad partes constitutivas del embargo como tal. No debe olvidarse, por otra parte, que el art. 450 del Código de Procedimiento Civil determina claramente que el embargo se entiende hecho "por la entrega real o simbólica de los bienes al depositario que se designe...".

\section{La realización de bienes embargados}

La segunda parte del libro, se dedica al estudio de la realización de los bienes embargados para hacer pago al ejecutante. Hay un tratamiento de todos los trámites y diligencias que implica la enajenación forzosa de las especies embargadas: tasación, bases del remate, el acta de remate, la escrituración, consignación de los fondos, liquidación del crédito y pago al acreedor. Se observa también un estudio especial de la citación de los acreedores hipotecarios a los efectos de la purga de la hipoteca, así como del saneamiento de la evicción y de los vicios redhibitorios de la cosa enajenada forzadamente. 
Prosigue la monografía con un análisis de la llamada tercería de prelación, que permite la concurrencia en el pago de un acreedor preferente. Sus últimas páginas están destinadas a otras formas de ejecución como son la adjudicación en pago y la anticresis judicial o prenda pretoria.

\section{4. ¿Es la venta forzada un contrato de compreventa?}

Numerosos son los aportes personales al desarrollo de nuestra doctrina, que el autor realiza en esta breve pero enjundiosa obra. Imposible revisarlos todos en un comentario como éste. No quisiéramos, sin embargo, dejar de mencionar la que nos parece más relevante. Se trata de la calificación jurídica de la enajenación forzosa de los bienes en embargados.

El profesor Navarrete con evidente audacia intelectual y acogido los criterios de la doctrina procesal española, se rebela contra la opinión tan extendida, de indudable raigambre histórica, e incluso sancionada normativamente, de que la enajenación judicial no es más que una compraventa forzada, en la que el juez actúa a nombre y en representación del deudor, que así, contra su voluntad, asume el rol jurídico de vendedor.

Navarrete comparte las críticas que se han hecho en el extranjero a esta teoría, y prefiere concebir la realización de bienes como un acto procesal de ejecución, en que el poder jurisdiccional del juez ordena y produce la transferencia de los bienes del patrimonio del deudor ejecutado al tercero que lo subasta. Con esta teoría, el autor critica la exigencia que hace nuestro Código de Procedimiento de que la enajenación forzosa sea completada mediante el otorgamiento de una escritura pública donde deben insertarse los principales documentos del proceso de ejecución. Sostiene que es posible sustituir la escritura pública por una resolución judicial, que tenga acceso al registro conservatorio.

La cuestión cuya revisión propone el autor no es ignorada tampoco por los civilistas, aunque tenga su origen en las reflexiones de los procesalistas. El colombiano Hernán Valencia Restreppo en su Teoría General de la Compraventa (Temis, Bogotá, 1983), sostiene sin miramientos que la llamada "venta forzada" no constituye una propia compraventa, siendo ésta una construcción artificial e inconveniente. Cuando más llega a admitir, siguiendo a Carnelutti y Devis Echandía, que se trata de un contrato procesal innominado (págs. 95-96).

Entre nosotros, Raúl Díez Duarte, La compraventa en el Código Civil Chileno, ( Conosur, Santiago, $2^{\circ}$ edic., s.f.) piensa, en cambio, que "Las compraventas forzadas son verdaderos contratos de compraventa. Entre las ventas forzadas no hay más diferencias, dentro de la teoría general del contrato, que en estas últimas, el vendedor, por ficción de la ley, es representado por el juez; que el precio se determina por las posturas que formulan los interesados que concurren al remate y las disposiciones especiales contenidas en los artículos 1851, 1865 y 1891 del Código Civil " (págs. 355-356). No obstante, admite que descle un punto de vista procesal la venta forzada es un acto jurídico mixto, es decir, presenta caracteres de acto civil y de actuación procesal, y de allí se sigue el doble régimen de impugnación en caso de vicios de nulidad. Esta posición ha sido refrendada por la jurisprudencia (RDJ T. 11 , sec. $1^{\circ}$, p. 206; t. 17, se. $1^{\circ}$, p. 344; t. 53, sec. $1^{\circ}$, p 44).

Sin intentar resolver esta cuestión, nos parece muy estimulante la invitación del profesor Navarrete en cuanto a reconsiderar la calificación jurídica de la enajenación 
forzada, ya sea para abandonar, como él propone, la tesis de la venta, o para reformularla sobre bases más consistentes, que la mera ficción de voluntad o la representación legal.

Un camino interesante que podría explorarse para hacer más luz en este problema, sería el de conducir este supuesto a la figura del contrato forzoso, concepto bajo el cual se agrupan casos en los que la ley obliga a celebrar un contrato o lo tiene por constituido con prescindencia de la voluntad de las partes. Como sostiene el profesor Jorge López Santa María es posible distinguir el contrato como "acto de constitución de la relación jurídica" y como "relación jurídica constituida", no siendo posible restringir la fuente de esta última al mero acuerdo de voluntades (Los Contratos. Parte general, Editorial Jurídica de Chile, Santiago, 1986, págs. 133 y ss.). Es posible entonces compaginar la noción de contrato de compraventa surgido por obra de, no de un acuerdo de voluntades, sino de un acto procesal revestido de ese imperio por la ley, acompañada de la voluntad del adjudicatario, que no puede adquirir derechos sin su voluntad.

En cualquier caso, se echa de menos en el libro que comentamos una referencia a las normas constitucionales que resultan relevantes en la materia, y en especial a la disposición del art. 19, № 24 de la Constitución Política que reconoce en la expropiación la única causa de pérdida justificada del dominio. La teoría que ve en la realización forzada no un contrato de compraventa, sino un acto de autoridad, encuentra una dificultad evidente frente a ese imperativo constitucional, que no resulta posible soslayar.

\section{Epilogo}

Que nos excuse el autor estas observaciones, que en ningún caso pretende desconocer el mérito de su trabajo. Más bien, su exposición busca poner de manifiesto que obras como el nuevo libro del profesor Navarrete deben ser saludadas justamente porque nos permiten reflexionar sobre problemas que no habíamos advertido y nos ayudan a vencer la pereza intelectual que tanto daño hace al desarrollo de nuestra doctrina jurídica. 